\title{
Atopic Dermatitis and Patient Perspectives: Insights of Bullying at School and Career Discrimination at Work
}

\author{
Luca Stingeni (iD) \\ Anna Belloni Fortina $\left(\mathbb{D}^{2}\right.$ \\ Ilaria Baiardini $\mathbb{D}^{3,4}$ \\ Katharina Hansel (D) \\ Devis Moretti ${ }^{5}$ \\ Filippo Cipriani $\mathbb{I D}^{5}$ \\ 'Dermatology Section, Department of \\ Medicine and Surgery, University of Perugia, \\ Perugia, Italy; ${ }^{2}$ Unit of Dermatology, \\ Department of Medicine - DIMED, \\ University of Padua, Padua, Italy; \\ ${ }^{3}$ Respiratory Unit for Continuity of Care, \\ IRCCS, Ospedale Policlinico San Martino, \\ Genova, Italy; ${ }^{4}$ Personalized Medicine \\ Asthma, \& Allergy Clinic, IRCCS Humanitas \\ Research Hospital, Rozzano, Milan, Italy; \\ ${ }^{5}$ Sanofi Genzyme, Sanofi S.r.l., Milan, Italy
}

Background: Atopic dermatitis (AD) is a chronic inflammatory skin disease characterized by recurrent eczematous lesions and intense pruritus. AD patients are known to face a considerable disease burden, including physical and emotional limitations. There is still limited knowledge about daily implications in education and occupation. We describe disease social stigmatization by measuring bullying and self-isolation in students and professional discrimination in workers. Overall loss of productivity, either at school and the workplace, was quantified as the sum of absenteeism (number of days AD sick leave) and presenteeism (number of days with decreased focus and functionality).

Methods: An on-line web survey was sent to 3235 random recipients and 401 met the inclusion criteria (self-reporting $\mathrm{AD}$ and $\geq 12$ yo). The survey domains included daily limitations, QoL, feelings and relationships, together with specific questions about bullying, discrimination and loss of productivity.

Results: AD negatively affected QoL in $51.6 \%$ of respondents, whereas $68.8 \%$ considered $\mathrm{AD}$ as a real limit to daily routine. More in detail, 39.3\% of students were victims of bullying and $33.9 \%$ of workers felt discriminated because of AD. On average, absenteeism in students was for 17.1 days/year (presenteeism: 19.5 days/year), whereas in workers, the estimate was 10.9 days/year (presenteeism: 13.1 days/year). Absenteeism and presenteeism were more pronounced in bullied/discriminated subjects.

Conclusion: AD multidimensional implications deeply affect and undermine personal and professional fulfillments. Our results contribute to a better understanding of what living with $\mathrm{AD}$ means.

Keywords: atopic dermatitis, discrimination, absenteeism, presenteeism

\section{Introduction}

Atopic dermatitis (AD) is a chronic, multifactorial inflammatory skin disease characterized by recurrent eczematous lesions and intense pruritus and affecting up to $20 \%$ of children and $8 \%$ of adults in Western countries. ${ }^{1,2}$ In children, disease onset occurs in $60 \%$ of cases prior to 1 year of age, ${ }^{3}$ without difference between genders, ${ }^{4}$ with patients continuing to suffer from $\mathrm{AD}$ in adulthood; on the other hand, more than $20 \%$ of adult AD patients suffer from "adult-onset" AD.

Recently, lichenified and exudative flexural dermatitis, sometimes in combination with portrait dermatitis, was reported more frequently in childhood onset $A D$, whereas prurigo nodularis-like and nummular eczema-like phenotypes in adult onset $\mathrm{AD} .^{6}$ Emotional burden of $\mathrm{AD}$ is widely documented with consequences on
Correspondence: Anna Belloni Fortina Unit of Dermatology, Department of Medicine - DIMED, University of Padua, Via Gallucci, 4, Padova, 35I28, Italy Email anna.bellonifortina@unipd.it 
the psychological well-being of patients, in analogy with other chronic skin diseases. ${ }^{7}$ AD children might develop emotional difficulties more frequently than kids with diabetes or asthma, and emotional-relational disorders comprise low self-esteem, behavioral and attachment disorders and socialization difficulties. ${ }^{8,9}$ Irritability and inattention are mainly caused by sleep loss because of frequent and severe itching with a risk of depression, anxiety, attention deficit hyperactivity disorder, and conduct disorders in children and adolescents. ${ }^{10,11}$ Furthermore, a decrease in quality of life (QoL) is linked to the association between sleep loss and depression. ${ }^{12}$

Disease severity is a barrier for peer-to-peer relations: kids with severe $\mathrm{AD}$ have fewer friends during primary and secondary school than those with moderate AD, and less often belong to a sport club but, in parallel, they tend to spend more time alone. ${ }^{13}$ School performance can be undermined as a result of missed schooldays, particularly in adolescents, with repercussions on future achievements. ${ }^{14} \mathrm{AD}$ adolescents also present severe difficulties in interpersonal relationships. ${ }^{15}$

In relational context, bullying is also described, ${ }^{16}$ with an estimated range from $10 \%$ to $60 \% .^{17,18}$ This variability is based on differences in the definition of bullying itself (generally described as a repetitive verbal, physical or social abuse), in the methodology (eg the inclusion of cyber-bullying), as well as in cultural and social background. However, it seems that bullying is consistently more pronounced in adolescents and in severe AD patients. ${ }^{19}$ Moving into adulthood, AD continues to negatively affect sleep and QoL. Adults with AD present a predisposition to develop depression and anxiety. ${ }^{20,21}$ AD can cause considerable working impairment, as a contribution to both sick leave and lower work efficiency. AD patients experience higher rates of absenteeism, and reduced productivity levels (presenteeism) rates compared to non-AD controls. ${ }^{14,22}$ In a recent crosssectional survey, AD severity was positively associated with more sick leave and greater loss of productivity. ${ }^{23}$ Finally, AD also compromises the ability to undertake some specific jobs, such as front office positions, or tasks, such as using irritating chemicals. ${ }^{24}$

Recently, Italian dermatologists have worked intensively on the harmonization of AD diagnosis and management in adults ${ }^{25}$ and in adolescents ${ }^{26}$ with great emphasis on social isolation, bullying and reduced level of attention at school. Since no recent data were available, to better explore these aspects, in this study we aimed to investigate $\mathrm{AD}$ QoL, feelings and interpersonal relationships across adolescence and adulthood both at school and at the workplace, inquiring about the frequency of bullying and self-isolation episodes among students and professional discrimination among workers.

\section{Materials and Methods}

\section{Patients Enrollment and Characteristics}

The survey sample was sourced from Doxa Population Panel, a proprietary quality-checked database representative of the Italian population from a socio-demographic point of view. An on-line questionnaire was randomly sent by email to 3235 subjects. Four hundred and one matched the predefined inclusion criteria (age $\geq 12$ and selfreporting to suffer from $\mathrm{AD})$. The highest representation was in the South (34.2\%), followed by North-West (25.9\%), Center (20.2\%) and North-East (19.7\%).

The final sample included 200 youngsters $(\leq 24$ years old) and 201 adult ( $\geq 25$ years old) patients. The age distribution was $12-15$ years in 50 (12.5\%), 16-18 years in $48(12.0 \%), 19-24$ years in $101(25.2 \%), 25-34$ years in $54(13.5 \%), 35-44$ years in $55(13.7 \%), 45-54$ years in 53 $(13.2 \%),>54$ years in $40(9.9 \%)$. To specifically explore presenteeism/absenteeism as well as the experience of self-isolation/bullying at school and discrimination at work, we identified upfront two further sub-groups: students $(163,47.1 \%)$ and workers $(183,52.9 \%)$. The remaining 55 patients were unemployed or retired. Demographic and clinical data are reported in Table 1.

\section{Study Design}

An online semi-structured interview (CAWI: Computer Assisted Web Interviewing) with a script-based technique was used for the study. The survey domains were based on literature review and 7 deep-dive ethnographic interviews (Table S1).

The CAWI script, approximately 20 minutes long, included open questions, 5-point Likert-scale questions, multiple-choice questions, closed questions (yes/no), and evaluation scale questions (e.g. 1 to 10 ). QoL has been investigated as feelings, stress and stigmatization. Impact of $\mathrm{AD}$ at school has been measured as relational difficulty with peers, bullying and self-isolation behaviors. Questions about bullying were neither direct nor explicit. In analogy, the impact at work has been investigated in the dimensions of relational difficulty and limitations that $\mathrm{AD}$ causes in work activities and overall job career. 
Table I Demographic and Clinical Data of Atopic Dermatitis Patients

\begin{tabular}{|c|c|c|c|c|}
\hline \multirow[t]{2}{*}{ No. Patients (\%) } & \multicolumn{2}{|c|}{ No. Patients $40 \mathrm{I}$} & \multicolumn{2}{|c|}{ No. Patients 346* } \\
\hline & Youngsters 200 (49.9) & Adults 201 (50.1) & Students I63 (47.I) & Workers I 83 (52.9) \\
\hline Mean age (SD) & $18.3( \pm 3.9)$ & $43.7( \pm 11.5)$ & $17.9( \pm 4.0)$ & $39.6( \pm 12.3)$ \\
\hline Females (\%) & $112(56.0)$ & $132(65.7)$ & $86(52.8)$ & $113(61.7)$ \\
\hline Males (\%) & $88(44.0)$ & $69(34.3)$ & $77(47.2)$ & $70(38.3)$ \\
\hline AD diagnosis: meantime (SD) & $10.2( \pm 5.1)$ & $14.7( \pm 11.8)$ & $12.1( \pm 7.3)$ & $21.1( \pm 15.4)$ \\
\hline Itch presence (\%) & $184(92.0)$ & $166(82.6)$ & $153(93.9)$ & I 46 (79.8) \\
\hline $\begin{array}{l}\text { Itch intensity }{ }^{\circ}(\%) \\
\text { From } 8 \text { to } 10 \\
\text { From } 6 \text { to } 7 \\
\text { From } 0 \text { to } 5\end{array}$ & $\begin{array}{l}64(32.0) \\
98(49.0) \\
38(19.0)\end{array}$ & $\begin{array}{l}66(32.9) \\
91(45.3) \\
44(21.9)\end{array}$ & $\begin{array}{l}49(30.1) \\
84(51.5) \\
30(18.4)\end{array}$ & $\begin{array}{l}61(33.4) \\
81(44.2) \\
41(22.4)\end{array}$ \\
\hline $\begin{array}{l}\text { Itch frequency }{ }^{\circ}(\%) \\
\text { From } 8 \text { to } 10 \\
\text { From } 6 \text { to } 7 \\
\text { From } 0 \text { to } 5\end{array}$ & $\begin{array}{l}71(35.5) \\
95(47.5) \\
34(17.0)\end{array}$ & $\begin{array}{l}69(34.4) \\
94(46.7) \\
38(18.9)\end{array}$ & $\begin{array}{l}54(33.1) \\
84(51.5) \\
25(15.4)\end{array}$ & $\begin{array}{l}55(30.1) \\
89(48.6) \\
39(21.3)\end{array}$ \\
\hline AD treated patients $\S$ & $189(94.5)$ & $180(89.6)$ & $|4|(86.5)$ & $1129(70.5)$ \\
\hline $\begin{array}{l}\text { AD treatments (\%) } \\
\text { Corticosteroids** } \\
\text { Topical non } \\
\text { Corticosteroid drugs } \\
\text { Antihistamines } \\
\text { Immunosuppressant } \\
\text { Drugs } \\
\text { Biological drugs }\end{array}$ & $\begin{array}{c}86(43.0) \\
136(68.0) \\
79(39.5) \\
16(8.0) \\
5(2.5)\end{array}$ & $\begin{array}{l}38(18.9) \\
74(36.8) \\
56(27.8) \\
22(11.0) \\
12(6.0)\end{array}$ & $\begin{array}{c}74(45.4) \\
122(74.9) \\
69(42.3) \\
9(5.5) \\
2(1.2)\end{array}$ & $\begin{array}{l}38(20.8) \\
63(34.4) \\
53(29.0) \\
25(13.7) \\
14(7.7)\end{array}$ \\
\hline
\end{tabular}

Notes: *The remaining 55 patients were unemployed or retired; ${ }^{\circ}$ scale from 0 to 10; §at least I atopic dermatitis drug during the past I year; **Topical or oral.

Presenteeism and absenteeism were measured as the number of days missed and with decreased productivity. Overall work/study impairment was considered as the sum of presenteeism and absenteeism. Internal consistency of the questions for students and for workers has been evaluated using Cronbach's alpha coefficient $(0.920$ and 0.976 , respectively).

All comparisons between age groups were decided upfront.

The $\chi^{2}$ test with Yates' continuity correction and Fisher's exact test were used to analyse categorical variables. Statistical analysis was performed using Diana software version 2.06.019 (NIPO, Amsterdam, The Netherlands). In all analyses, a two-sided $P$ value $\leq 0.05$ was considered to be significant.
Informed consent was provided by all patients enrolled in the study. In the case of minor participants, a parent provided consent and was also present during the survey.

\section{Results}

In $90.8 \%$ of cases $\mathrm{AD}$ was localized in visible areas: hands, arms and scalp were the most quoted localizations. More than $50 \%$ of the body surface area (BSA) was affected by $\mathrm{AD}$ in $17.5 \%$ of patients. Among signs and symptoms, itch was by far the most frequent (87.3\%), followed by dry (76.1\%) and rough skin (73.8\%), cutaneous rash $(67.3 \%)$, and pain $(46.9 \%)$. Not surprisingly, itch was the most difficult symptom to cope with $(55.7 \%)$, followed by pain $(26.1 \%)$ and bleedings $(24.3 \%)$. 


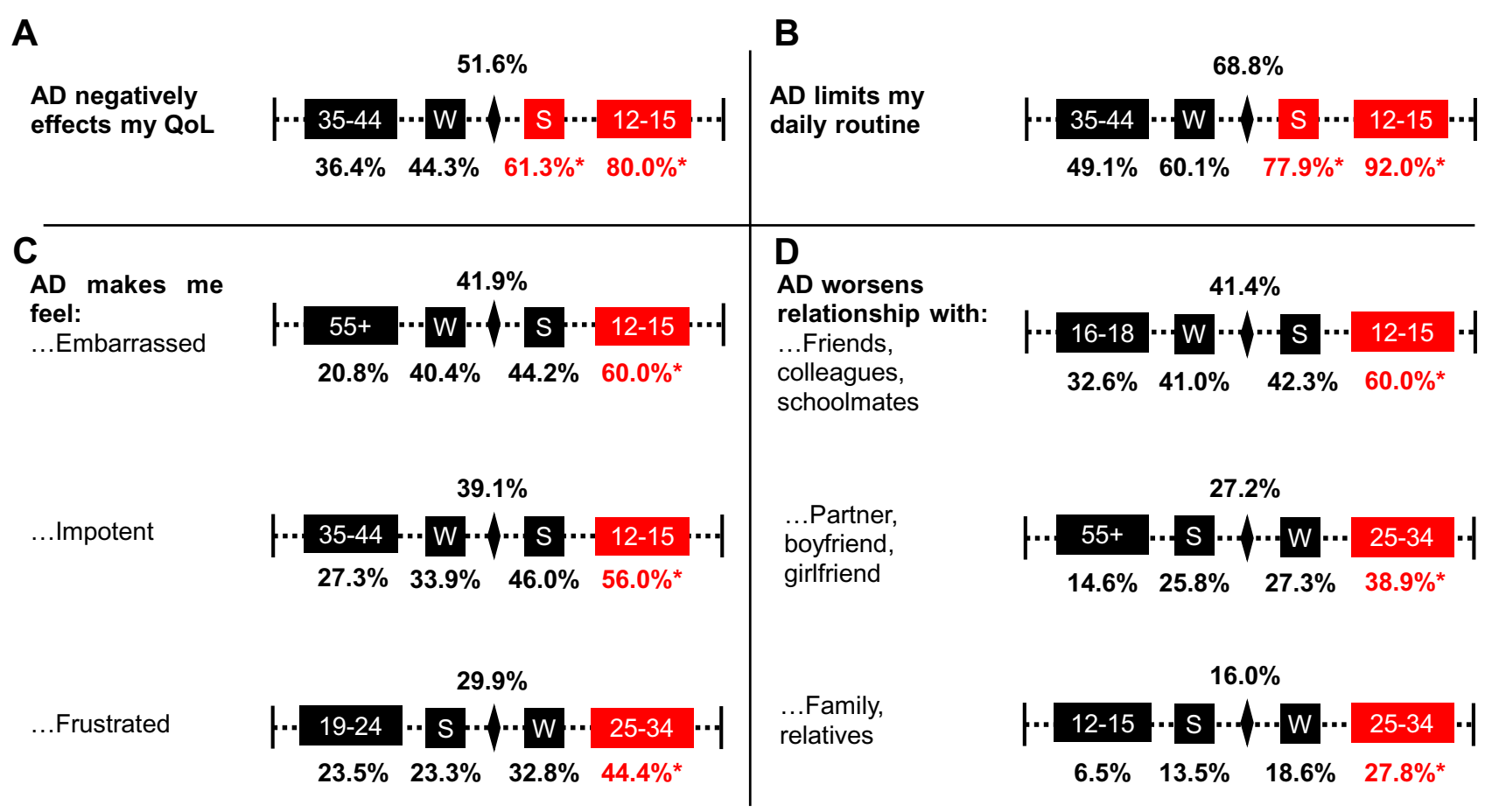

Figure I Quality of life, daily limitations, feelings and relationships.

Notes: Questions were asked specifically about AD social consequences such as effect on QoL perception (panel A), limitation in daily activities (pane B), feelings (panel C) and interpersonal relationships (panel D). The diamond refers to all population (40I). Boxes refer to age groups. QoL pooled answers $5 / 4$ in a I ("not at all”) to 5 ("highly") scale. Feelings refer to pooled answers "always"/“often" in the past 4 weeks. Relationships refer to pooled answers "very much"/“enough". *Statistically significant ( $\leq 0.05$ ) Abbreviations: W, workers (183); S, students (163).

\section{QoL, Daily Limitations, Feelings, and Relationships}

In everyday life, $51.6 \%$ of $\mathrm{AD}$ patients reported a reduced QoL, whereas $68.8 \%$ considered $\mathrm{AD}$ as a real limit to daily routine (Figure 1A and B). Both perceptions were statistically more frequent among students $(61.3 \%$ and $77.9 \%$, $\mathrm{p}<0.05)$. Embarrassment (41.9\%), impotence (39.1\%) and frustration $(29.9 \%)$ were overall the most quoted feelings associated with AD (Figure 1C).

AD had an impact, especially in early adolescence and early adulthood. The $12-15$ age group reported an even higher impact on the QoL $(p<0.05)$, together with experiences of embarrassment $(\mathrm{p}<0.05)$, impotence $(p<0.05)$ relational avoidance $(p<0.05)$ and disparity $(p<0.05)$. Furthermore, $92.0 \%$ experienced limitations in daily routine $(\mathrm{p}<0.05)$, particularly on sports and free time activities $(\mathrm{p}<0.05)$, social relationships $(p<0.05)$, perception on general state of health $(p<0.05)$. Finally, the $12-15$ year-group more often reported stress related to $\mathrm{AD}$ signs and symptoms $(p<0.05)$, that in return negatively affected the pathology $(\mathrm{p}<0.05)$ in a vicious circle.
In early adulthood (25-34 age group), patients more often experienced a sense of frustration linked to the pathology $(\mathrm{p}<0.05)$, difficulties in relationship with partner $(\mathrm{p}<0.05)$ and family members $(\mathrm{p}<0.05)$ (Figure $1 \mathrm{D})$.

\section{Bullying and Self-Isolation}

AD students were frequently targeted with nicknames $(31.3 \%)$ and jokes $(30.1 \%)$ by classmates who were also excluding/isolating $(22.1 \%)$ or being bossy $(22.1 \%)$ with them. Overall, $39.3 \%$ has experienced at least few episodes of direct bullying at school in the previous year (Figure 2A). 65.6\% referred self-isolation behaviors; $51.5 \%$ found too complex to interact with classmates of the opposite sex, $44.2 \%$ avoided parties, $42.3 \%$ gave up on other school activities and $28.8 \%$ missed schooldays in order to avoid potential bullying situations (Figure 2B). Self-isolation was more frequent in presence than in absence of bullying $(96.9 \%$ vs $45.5 \% ; \quad \mathrm{p}<0.05)$. Altogether $66.9 \%$ have experienced at least one episode of direct bullying or self-isolation (Figure 2C) related to $\mathrm{AD}$ in the previous year $(63.5 \%$ in the previous month). Bullying or self-isolation was more frequent in males $(76.6 \% ; \mathrm{p}<0.05)$ and in the $12-15$ age-group 
A

My schoolmates gives nicknames linked to $A D$

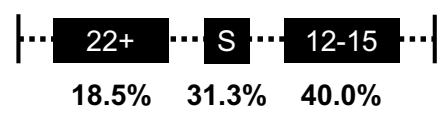

My schoolmates laugh at me because of $A D$

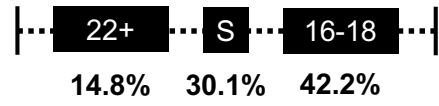

My schoolmates isolate/exclude me because of $A D$

My schoolmates are bossy with me because of $A D$

Any AD related bullying experience
B

I struggle to relate to peers of opposite sex because of $A D$

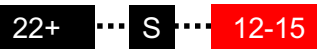

$29.6 \% \quad 51.5 \% \quad 68.0 \%$ *

I give up parties because of $A D$

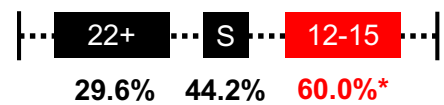

I give up school trips because of $A D$

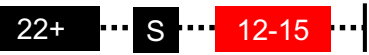

$18.5 \% \quad 42.3 \% \quad 66.0 \%$ *

I avoid to go to school because of $A D$

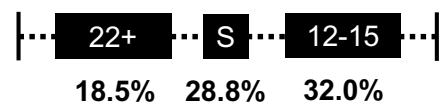

Any $A D$ related self-isolation behavior

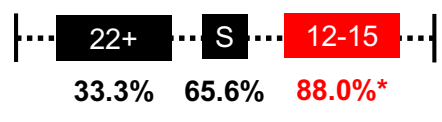

\section{C \\ Any bullying experience or self-isolation behavior due to $A D$}

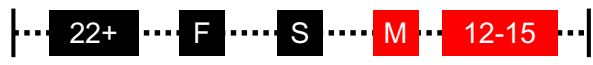 \\ $33.3 \% 58.0 \% 66.9 \% 76.6 \%$ * $88.0 \%$ *}

Figure 2 Bullying and self-isolation at school.

Notes: Students (S: 163) were asked specifically about episodes linked to bullying (panel A) or self-isolation (panel B).Overall AD burden bullying or self-isolation is presented in panel (C). Boxes refer to male (M), females (F) or age groups. Percentages are pulled answers "always"/"often"/"sometimes" and refer to the past I2 months. *Statistically significant $(\mathrm{p} \leq 0.05)$.

Abbreviations: $F$, females; $M$, males.

$(88.0 \% ; \mathrm{p}<0.05)$. This latter group reported more relational difficulties with the opposite sex $(68.0 \% ; \mathrm{p}<0.05)$, and more renounces (avoiding parties: $60.0 \%, \mathrm{p}<0.05$; other school-related events $66.0 \% ; \quad \mathrm{p}<0.05$ ). Interestingly, the memory of bullying remained vivid even in adulthood (55.2\%, all ages). The reminiscence was significantly higher in young adults $(73.2 \%$ in $25-$ 34 age-group, $\mathrm{p}<0.05)$ and faded over time $(46.0 \%$ in 55 + year-group).

\section{Absenteeism and Presenteeism at School}

When inquired about school attendance and performance in the last 12 months, $17.2 \%$ reported school absences, late entries or early exits due to $\mathrm{AD}$ for "one or more day per week", meaning minimum 50 days per year (Figure 3). $28.2 \%$ reported absenteeism for "few days every 2 weeks/ a few days a month" (15 to 30 days per year) and 54.6\% for "few days per year". Overall, we calculated an average 17.1 days of absenteeism per student per year.

Regarding presenteeism, on average the impact was about 19.5 days per year. More in detail, 20.9\% recorded difficulties in keeping focus and concentration at school or doing homework at home for least "one or more day per week". 36.8\% declared to experience presenteeism for "few days every 2 weeks/few days a month", whereas the remaining $42.3 \%$ had an impaired study performance for "few days per year". The overall study impairment was 36.6 days per student per year.

Among all ages, absenteeism was more pronounced in $12-15$ year-group adolescents $(60.0 \%$ at least "few days a month"). This was coherent with a significantly higher presence of itch $(98.0 \%$ vs $87.3 \% ; \mathrm{p}<0.05)$ and sleep difficulties $(66.0 \%$ vs $29.7 \%$; $<<0.05)$ within the same age group.

\section{Association Between Bullying, Presenteeism/Absenteeism and QoL}

We found a positive association between bullying and presenteeism/absenteeism at school. Bullied students showed a more pronounced absenteeism $(61.5 \%$ vs $13.0 \% ; \mathrm{p}<0.05)$ as well as presenteeism $(71.6 \%$ vs $29.6 \% ; p<0.05)$. Significantly higher frequencies of bullying $(53.0 \%, \mathrm{p}<0.05)$, bullying and self-isolation $(90.0 \%$, 


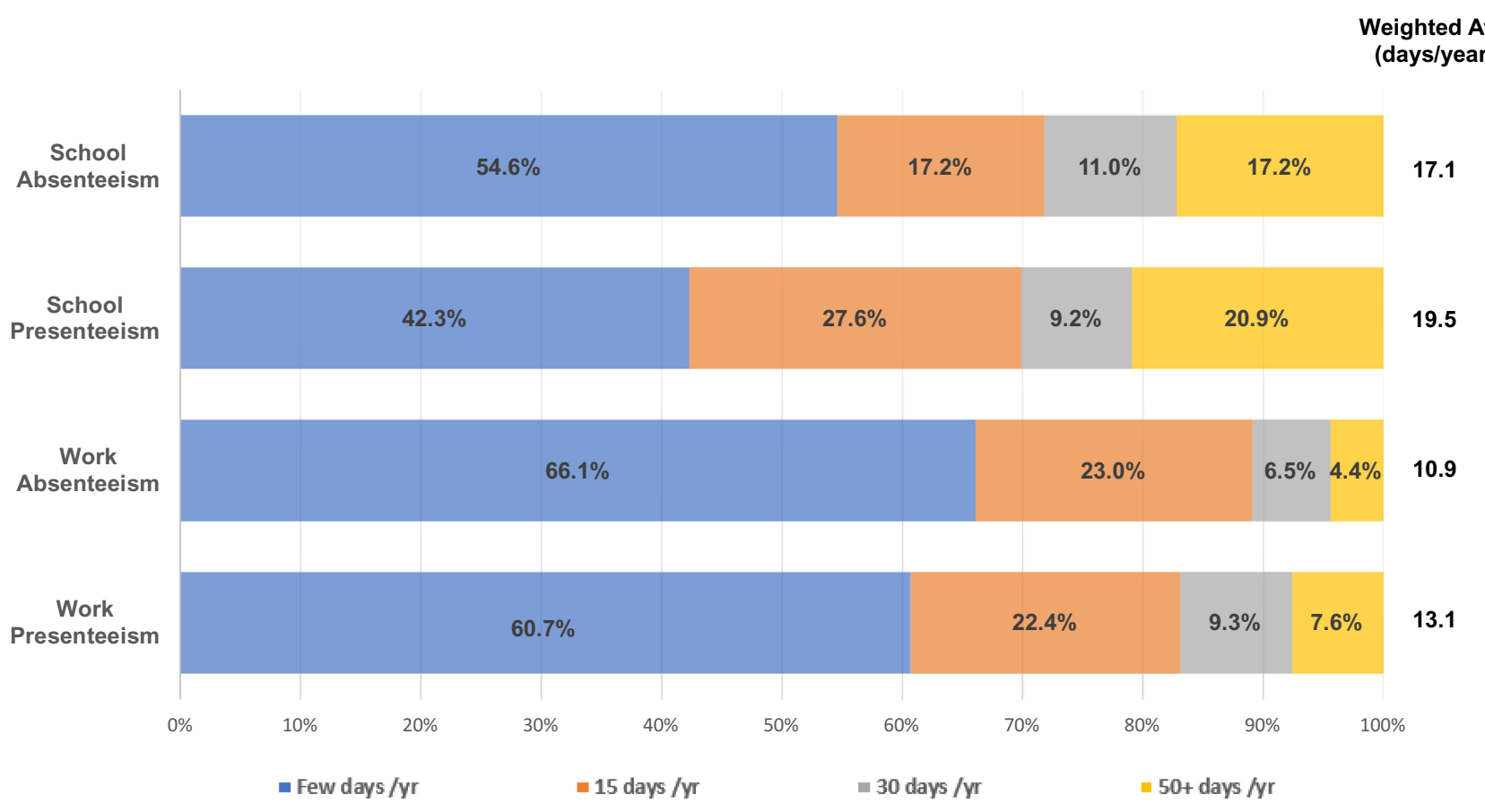

Figure 3 Absenteeism and presenteeism at school and at work.

Notes: Absenteeism was calculated as the number of days AD sick leave, whereas presenteeism was the number of days with decreased focus and functionality, either at school or at work.

A Without AD I could be
more productive

$A D$ causes stress and that makes my job difficult

I have to refuse some duties/tasks because of $A D$

I must renounce to business trips because of $A D$

$A D$ will limit my career development
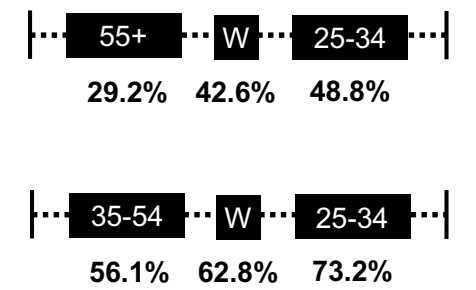
f.. $55+\ldots . . .+25-34$ $24.1 \% \quad 34.4 \% \quad 43.9 \%$

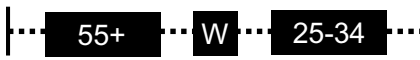 $20.9 \% \quad 36.6 \% \quad 51.2 \%$}

My colleagues think they can take advantage of me because of $A D$

B

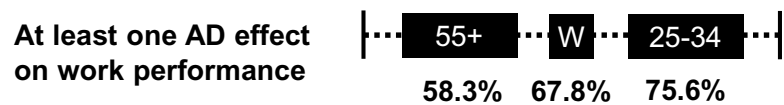

\section{C}

I am not trusted with some duties/tasks because of $A D$

$55+\cdots W \cdots 25-34$

$20.8 \% \quad 29.0 \% \quad 31.7 \%$

My colleagues laugh at me because of $A D$

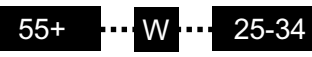

$12.5 \% \quad 22.4 \% \quad 29.3 \%$

19-24 ...W W... 25-34

$10.3 \% 21.9 \% \quad 26.8 \%$ *

At least one episode of work

discrimination

55+ ...W $\cdots 25-34$

$20.8 \% \quad 33.9 \% \quad 46.3 \%$

Figure 4 Work performance and discrimination.

Notes: Workers (W: I83) were asked specifically about AD-related professional limitation (panel A). Overall impact on work performance was summarized in panel (B). In panel $(\mathbf{C})$, alternative situations of AD-related discrimination by employers/colleagues are presented. Boxes refer to age groups. Percentages are pulled answers "always"/ "often"/"sometimes" and refer to the past 12 months. *Statistically significant $(p \leq 0.05)$ 
$\mathrm{p}<0.05)$, absenteeism $(60.0 \%, \mathrm{p}<0.05)$ were associated with low QoL.

\section{Work Performance and Discrimination}

Regarding working performance, $42.6 \%$ could be more productive if not suffering from $\mathrm{AD}$, with $62.8 \%$ complaining that professional stress was a negative factor for $\mathrm{AD}, 34.4 \%$ and $30.1 \%$ had to renounce either some duties or to business trips, respectively. For $36.6 \%$ of workers $\mathrm{AD}$ posed an obstacle for career development (Figure 4A). Overall, $67.8 \%$ has experienced negative professional implications in the previous year due to $\mathrm{AD}$ (Figure $4 \mathrm{~B}$ ).

About prejudices at the workplace, $29.0 \%$ were not trusted to perform some duties or tasks. Additionally, colleagues have been perceived to laugh (22.4\%) and to take advantage of $\mathrm{AD}$ workers (21.9\%). Overall, in $33.9 \%$ of cases, there was the perception of being victim of at least one episode of discrimination at work due to $A D$ (Figure 4C). Only 1 patient out of 2 openly disclosed to suffer from $\mathrm{AD}$ at work. Such attitude was less pronounced in young workers (26.8\% in 25-34 year-group vs $66.7 \%$ in $45-54$ year-group; $p<0.05$ ). Finally, $9.3 \%$ did not get a desired job because of AD.

\section{Absenteeism and Presenteeism at Work}

In the previous year, workers reported on average 10.9 days of absence because of AD. More specifically $4.4 \%$ of workers declared absence, late entries or early exits for "one or more day per week" and $29.5 \%$ for "few days every 2 weeks/a few days per month". The residual $66.1 \%$ referred absenteeism for "few days per year". Each worker also declared on average 13.1 days of impaired productivity. $60.7 \%$ experienced presenteeism for "few days per year", $31.7 \%$ for 15 to 30 days a year, whereas $7.6 \%$ for at least 50 days per year. The overall work impairment (the aggregate of absenteeism and presenteeism) was 24.0 days per worker per year.

Interestingly, $78.9 \%(\mathrm{p}<0.05)$ of workers who have been absent or not very productive because of $\mathrm{AD}$ recalled having been bullied at school and $68.4 \%(\mathrm{p}<0.05)$ reported a concomitant experience of discrimination at work.

\section{Association Between Professional Discrimination, Presenteeism/ Absenteeism and QoL}

In analogy with bullied students, discriminated workers reported a more pronounced absenteeism $(67.7 \%$ vs
$16.5 \% ; \mathrm{p}<0.05)$ as well as presenteeism $(71.0 \%$ vs $23.1 \% ; \mathrm{p}<0.05)$ compared to non-discriminated ones. Significantly higher frequencies of discrimination $(58.0 \%, \mathrm{p}<0.05)$, absenteeism $(55.6 \%, \mathrm{p}<0.05)$, and presenteeism $(64.2 \%, \mathrm{p}<0.05)$ were found in workers reporting low QoL.

\section{Discussion}

This study on patient-reported AD burden in Italy explores the educational and working context, providing novel insights, in both youngsters and adults.

Our analysis shows a significant negative impact of $A D$ on self-confidence and daily choices. Embarrassment, impotence and frustration are the most quoted feelings associated with AD. Such feelings might explain the reported difficulties in establishing and maintaining relationships with family members, partners and friends, as well as schoolmates and colleagues. One patient out of 2 has a perception of impaired QoL. Such feeling is more frequently reported by students (6 out of 10) and particularly in those $12-15$-year-old ( 8 out of 10 ). $68.8 \%$ of all $\mathrm{AD}$ patients consider $\mathrm{AD}$ as a real limit to daily life (sport, free activities), particularly youngest teenagers $(92.0 \%)$. AD negatively undermines emotional wellbeing, contributing to social stigma and susceptibility to stress. Our data are in line with a recent European study on 1189 adult AD patients, in which 55.0\% reported a moderate to extremely large impairment in quality of life and $88.0 \%$ of patients with severe $\mathrm{AD}$ reported a compromised ability to face life. ${ }^{24}$ In this study, we documented the distress at school and in the occupational environment by deep diving into students and workers. Among students, 39.2\% feel bullied because of $A D$, whereas $33.9 \%$ of workers recall one or more episodes of AD-related professional discrimination, with colleagues taking advantage or mocking with jokes. We also document an association between memories of bullying at school and current experience of discrimination in the workplace.

Self-isolation behaviors are also quite frequent with 7 out of 10 students giving up on social activities, such as attending parties or school trips. Such renounces are more frequent in the 12-15-year-old subgroup. In addition, in $94.2 \%$ of adolescents bullying and self-isolation are both present, in line with documented relationship between skin diseases and adverse relational and psychological sequelae. $^{16}$ 
These aspects are similar to those referred by workers, for whom $67.8 \%$ reported negative professional implications, feeling limited in job performance or uncertain about career achievements and development. One worker out of 3 is not able to perform specific duties or renounces to business trips, whereas $42.6 \%$ could be more productive if not suffering from $\mathrm{AD}$, confirming the results of previous studies on the work life of patients with $\mathrm{AD}{ }^{27,28}$ Overall, we estimate a negative effect on 1 of 3 workers, as recently demonstrated. ${ }^{24}$

Recurrent episodes of absenteeism and presenteeism are present both among students and workers. On average, students miss 17.1 days of school per year and have 19.5 days per year of impaired focus and concentration. Absenteeism and presenteeism are all amplified in youngest students. Six adolescents out of 10 have a negative impact for few days per month, nearly 30 days/year, in line with a previous observation (26 days of school lost). ${ }^{13}$ In strict analogy, workers report on average 10.9 days of absence and 13.1 days of impaired productivity because of AD. Ring et al recently showed that $25.0 \%$ of adult AD patients missed more than 6 days per year, ${ }^{24}$ whereas Andersen et al reported in severe $\mathrm{AD}$ patients up to 0.5 days of absenteeism and 19.7 hours of presenteeism per week. ${ }^{23}$ Itch can easily explain the reduced focus on students and productivity in workers because of poor sleep quality at night and concentration during the day. ${ }^{29,30}$ Involvement of visible localizations can also undermine patient's self-confidence and willingness to go to school or work.

Inclusion at school and acceptance in the workplace should be encouraged in order to guarantee a proper education as well as a future job career: up to $38 \%$ of $\mathrm{AD}$ patients cannot pursue the desired studies or occupation. ${ }^{14}$ Our study also highlights the association between an unfriendly environment at school/work and poor attendance or performance. In our sample, bullied adolescents show less attendance and attention compared to not bullied ones. In parallel, discriminated workers show significantly higher rates of absenteeism and presenteeism compared to included ones and recall being the object of bullying at school. Despite further studies on a wider population are needed in order to unequivocally demonstrate a causeeffect link, this association should not be underestimated.

All our results emphasize that AD impacts especially in proximity of important life phases, such as early adolescence (12-15 years) and early adulthood/first working experiences (25-34 years). In these transitions, $\mathrm{AD}$ seems to constitute an additional hurdle that fuels personal uncertainty and insecurity, together with considerable difficulties in undertaking basic social activities. Young adolescents seem the most fragile, demanding further investigation in order to better understand and, consequently, to develop specific psycho-educational support interventions, ${ }^{31}$ not ignoring the personal and professional implications in caregivers as well as in siblings of $\mathrm{AD}$ patients.

The main limitation of our study is typical of patient surveys and consists in the self-reporting AD diagnosis by patients. Nevertheless, the enrollment was anonymous, blinded and responders did not know upfront that we were investigating $\mathrm{AD}$ since the screening questions also included other common diseases. Anonymization prevented us from re-contacting and asking for additional information. We are confident about the consistency of the final population because all signs and symptoms, including disease localizations, pharmacological treatments and comorbidities, are compatible with AD. Moreover, given that participants were self-reporting $\mathrm{AD}$ diagnosis, disease severity was not considered in our study. However, this is not necessarily a limitation because the survey aimed to represent the general picture of $\mathrm{AD}$ patients. In addition to memories of bullying in adults, all questions refer to the last month or last year, in order to minimize any recall bias, another possible shortcoming of retrospective studies. Finally, our interest was understanding $\mathrm{AD}$ impact on patient daily experience with specific impact on studying and working. Our survey was tailored specifically on $\mathrm{AD}$, not including matched control groups without $\mathrm{AD}$ or with other chronic skin diseases, but the exploratory nature of our work will hopefully draw further attention to the topic and encourage future studies.

In conclusion, this study is the first attempt in Italy to address the relevance of deep understanding of bullying at school and career discrimination at work in adolescent and adult $\mathrm{AD}$ patients. $\mathrm{AD}$ impacts transversely various aspects such as education and professional fulfilment and $A D$ patients can encounter prejudice, ignorance or misunderstanding about their condition. Knowledge of these aspects could be the first step in relieving the burden of disease.

\section{Statement of Compliance}

All procedures were in accordance with both international (ESOMAR and EphMRA) and national (FarmIndustria) ethical standards as well as with the 1964 Helsinki Declaration, its later amendments or comparable ethical standards. The survey did not require ethics approval from 
IRB/local ethics committee. Informed consent was obtained from all individual participants involved in the present study.

\section{Acknowledgments}

Interviews and statistical analysis performed by DOXApharma, funded by Sanofi S.r.1. Medical writing and editorial support provided by Antonella Demma, funded by Sanofi S.r.l.

\section{Author Contributions}

All authors made substantial contributions to conception and design, acquisition of data, or analysis and interpretation of data; took part in drafting the article or revising it critically for important intellectual content; agreed to submit to the current journal; gave final approval of the version to be published; and agreed to be accountable for all aspects of the work.

\section{Funding}

Research sponsored by Sanofi S.r.l.

\section{Disclosure}

L. Stingeni has served on advisory boards and received honoraria for lectures from AbbVie, Almirall, Celgene, Eli Lilly, Novartis, Sanofi Genzyme. A. Belloni Fortina has served on advisory boards from AbbVie, Galderma, Celgene, Eli Lilly, Novartis, Sanofi Genzyme. K. Hansel has served on advisory boards and received honoraria for lectures from AbbVie and Celgene. I. Baiardini IB reports scientific consultations and/or lectures from Boehringer Ingelheim, Chiesi Farmaceutici, GlaxoSmithKline, Menarini, Novartis, Sanofi Genzyme, Biofutura, Mundifarma, AstraZeneca. D. Moretti and F. Cipriani are Sanofi employees, may hold stock and/or stock options at the company.

\section{References}

1. Wollenberg A, Barbarot S, Bieber T, et al. Consensus-based European guidelines for treatment of atopic eczema (atopic dermatitis) in adults and children: part I. J Eur Acad Dermatol Venereol. 2018;32:657-682.

2. Silverberg JI, Barbarot S, Gadkari A, et al. Atopic dermatitis in the pediatric population: a Cross-sectional, International, Epidemiologic Study. Ann Allergy Asthma Immunol. 2021;126(4):417-428.e2. doi:10.1016/j.anai.2020.12.020

3. Kowalska-Olędzka E, Czarnecka M, Baran A. Epidemiology of atopic dermatitis in Europe. J Drug Assess. 2019;8:126-128. doi:10.1080/ 21556660.2019.1619570

4. Megna M, Patruno C, Balato A, Rongioletti F, Stingeni L, Balato N, Italian Adult Atopic Dermatitis Study Group. An Italian multicentre study on adult atopic dermatitis: persistent versus adult-onset disease. Arch Dermatol Res. 2017;309:443-452. doi:10.1007/s00403-017-1739-y
5. Ellis CN, Mancini AJ, Paller AS, Simpson EL, Eichenfield LF. Understanding and managing atopic dermatitis in adult patients. Semin Cutan Med Surg. 2012;31(3 Suppl):S18-S22. doi:10.1016/j. sder.2012.07.006

6. Nettis E, Ortoncelli M, Pellacani G, et al. A multicenter study on the prevalence of clinical patterns and clinical phenotypes in adult atopic dermatitis. J Invest Allergol Clin Immunol. 2020;30:448-472. doi:10.18176/jiaci.0519

7. Dalgard FJ, Gieler U, Tomas-Aragones L, et al. The psychological burden of skin diseases: a Cross-Sectional Multicenter Study among dermatological out-patients in 13 European countries. J Invest Dermatol. 2015;135(4):984-991. doi:10.1038/ jid.2014.530

8. Senra MS, Wollenberg A. Psychodermatological aspects of atopic dermatitis. Br J Dermatol. 2014;170(Suppl 1):38-43. doi:10.1111/ bjd. 13084

9. Beattie P, Lewis-Jones M. A comparative study of impairment of quality of life in children with skin disease and children with other chronic childhood diseases. Br J Dermatol. 2006;155(1):145-151. doi:10.1111/j.1365-2133.2006.07185.x

10. Na CH, Chung J, Simpson EL. Quality of life and disease impact of atopic dermatitis and psoriasis on children and their families. Children. 2019;6:133.

11. Slattery MJ, Essex MJ, Paletz EM, et al. Depression, anxiety, and dermatologic quality of life in adolescents with atopic dermatitis. $J$ Allergy Clin Immunol. 2011;128(3):668-671. doi:10.1016/j. jaci.2011.05.003

12. Fivenson D, Arnold RJ, Kaniecki DJ, et al. The effect of atopic dermatitis on total burden of illness and quality of life on adults and children in a large managed care organization. J Manag Care Pharm. 2002;8:333-342. doi:10.18553/jmcp.2002.8.5.333

13. Brenninkmeijer EE, Legierse CM, Sillevis Smitt JH, Last BF, Grootenhuis MA, Bos JD. The course of life of patients with childhood atopic dermatitis. Pediatr Dermatol. 2009;26:14-22. doi:10.1111/j.1525-1470.2008.00745.x

14. Holm EA, Esmann S, Jemec GB. The handicap caused by atopic dermatitis-sick leave and job avoidance. J Eur Acad Dermatol Venereol. 2006;20:255-259. doi:10.1111/j.1468-3083.2006.01416.x

15. Kwon JA, Park EC, Lee M, Yoo KB, Park S. Does stress increase the risk of atopic dermatitis in adolescents? Results of the Korea Youth Risk Behavior Web-based Survey. (KYRBWS-VI). PLoS One. 2013;8:e67890. doi:10.1371/journal.pone.0067890

16. Magin P. Appearance-related bullying and skin disorders. Clin Dermatol. 2013;3:66-71. doi:10.1016/j.clindermatol.2011.11.009

17. Hon KL, Leung TF, Wong KY, Chow CM, Chuh A, Ng PC. Does age or gender influence quality of life in children with atopic dermatitis? Clin Exp Dermatol. 2008;33(6):705-709. doi:10.1111/j.13652230.2008.02853.x

18. Lawson V, Lewis-Jones MS, Finlay AY, Reid P, Owens RG. The family impact of childhood atopic dermatitis: the dermatitis family impact questionnaire. $\mathrm{Br} \quad J$ Dermatol. 1998;138:107-113. doi:10.1046/j.1365-2133.1998.02034.x

19. Zuberbier T, Orlow SJ, Paller AS, et al. Patient perspectives on the management of atopic dermatitis. $J$ Allergy Clin Immunol. 2006;118:226-232. doi:10.1016/j.jaci.2006.02.031

20. Silverberg JI. Atopic dermatitis in adults. Med Clin North Am. 2020;104(1):157-176. doi:10.1016/j.mcna.2019.08.009

21. Rønnstad ATM, Halling-Overgaard AS, Hamann CR, Skov L, Egeberg A, Thyssen JP. Association of atopic dermatitis with depression, anxiety, and suicidal ideation in children and adults: a systematic review and meta-analysis. J Am Acad Dermatol. 2018;79:448-456. doi:10.1016/j.jaad.2018.03.017

22. Nørreslet LB, Ebbehøj NE, Ellekilde Bonde JP, Thomsen SF, Agner T. The impact of atopic dermatitis on work life a systematic review. J Eur Acad Dermatol Venereol. 2018;32 (1):23-38. doi:10.1111/jdv.14523 
23. Andersen L, Nyeland ME, Nyberg F. Increasing severity of atopic dermatitis is associated with a negative impact on work productivity among adults with atopic dermatitis in France, Germany, the U. K. and the U.S.A. Br J Dermatol. 2020;182:1007-1016. doi:10.1111/bjd.18296

24. Ring J, Zink A, Arents BWM, et al. Atopic eczema: burden of disease and individual suffering - results from a large EU study in adults. J Eur Acad Dermatol Venereol. 2019;33(7):1331-1340. doi: $10.1111 /$ jdv. 15634

25. Patruno C, Amerio P, Chiricozzi A, et al. Optimizing a clinical guidance for diagnosis of atopic dermatitis in adults: joint recommendations of the Italian Society of Dermatology and Venereology (SIDeMaST), Italian Association of Hospital Dermatologists (ADOI), and Italian Society of Allergological, Occupational and Environmental Dermatology (SIDAPA). G Ital Dermatol Venereol. 2020;155:1-7.

26. Calzavara-Pinton P, Belloni Fortina A, Bonamonte D, et al. Diagnosis and management of moderate to severe atopic dermatitis in adolescents. A Consensus by the Italian Society of Dermatology and Venereology (SIDeMaST), the Italian Association of Hospital Dermatologists and Public Health (ADOI), the Italian Association of Hospital and Territorial Allergists and Immunologists (AAIITO), the Italian Society of Allergy, Asthma and Clinical Immunology (SIAAIC), the Italian Society of Pediatric Allergy and Immunology (SIAIP), the Italian Society of Allergological, Occupational and Environmental Dermatology (SIDAPA), and the Italian Society of Pediatric Dermatology (SIDerP). G Ital Dermatol Venereol. 2020;153:133-145.
27. Eckert L, Gupta S, Amand C, Gadkari A, Mahajan P, Gelfand JM. Impact of atopic dermatitis on health-related quality of life and productivity in adults in the United States: an analysis using the national health and wellness survey. $J$ Am Acad Dermatol. 2017;77 (2):274-279. doi:10.1016/j.jaad.2017.04.019

28. Chizuko Y, Hidehisa S, Takaoki I, et al. Impact of disease severity on work productivity and activity impairment in Japanese patients with atopic dermatitis. J Dermatol. 2013;40:736-739. doi:10.1111/13468138.12220

29. Ramirez FD, Chen S, Langan SM, et al. Association of atopic dermatitis with sleep quality in children. JAMA Pediatr. 2019;173:5. doi:10.1001/jamapediatrics.2019.0025

30. Li JC, Fishbein A, Singam V, et al. Sleep disturbance and sleep-related impairment in adults with atopic dermatitis: a Cross-sectional Study. Dermatitis. 2018;29:270-277. doi:10.1097/ DER.0000000000000401

31. Slattery MJ, Essex MJ. Specificity in the association of anxiety, depression and atopic disorders in a community sample of adolescents. J Psychiatr Res. 2011;45:788-795.

\section{Publish your work in this journal}

The Journal of Asthma and Allergy is an international, peer-reviewed open-access journal publishing original research, reports, editorials and commentaries on the following topics: Asthma; Pulmonary physiology; Asthma related clinical health; Clinical immunology and the immunological basis of disease; Pharmacological interventions and new therapies. The manuscript management system is completely online and includes a very quick and fair peer-review system, which is all easy to use. Visit http://www.dovepress.com/testimonials.php to read real quotes from published authors. 